\title{
Enhanced Performance of High Energy Density Lithium Metal Battery with PVDF- HFP/LAGP Composite Separator
}

Tian Liang ${ }^{\dagger, \ddagger}$, Wei-Hua Liang ${ }^{\dagger}$, Jian-Hua Cao ${ }^{\dagger}$, Da-Yong $W u^{\dagger *}$

$\dagger$ Technical Institute of Physics and Chemistry, Chinese Academy of Science, 29

Zhong-Guan-Cun East road, Haidian District, Beijing 100190, P. R. China

$\$$ University of Chinese Academy of Science, Beijing 100049, P. R. China
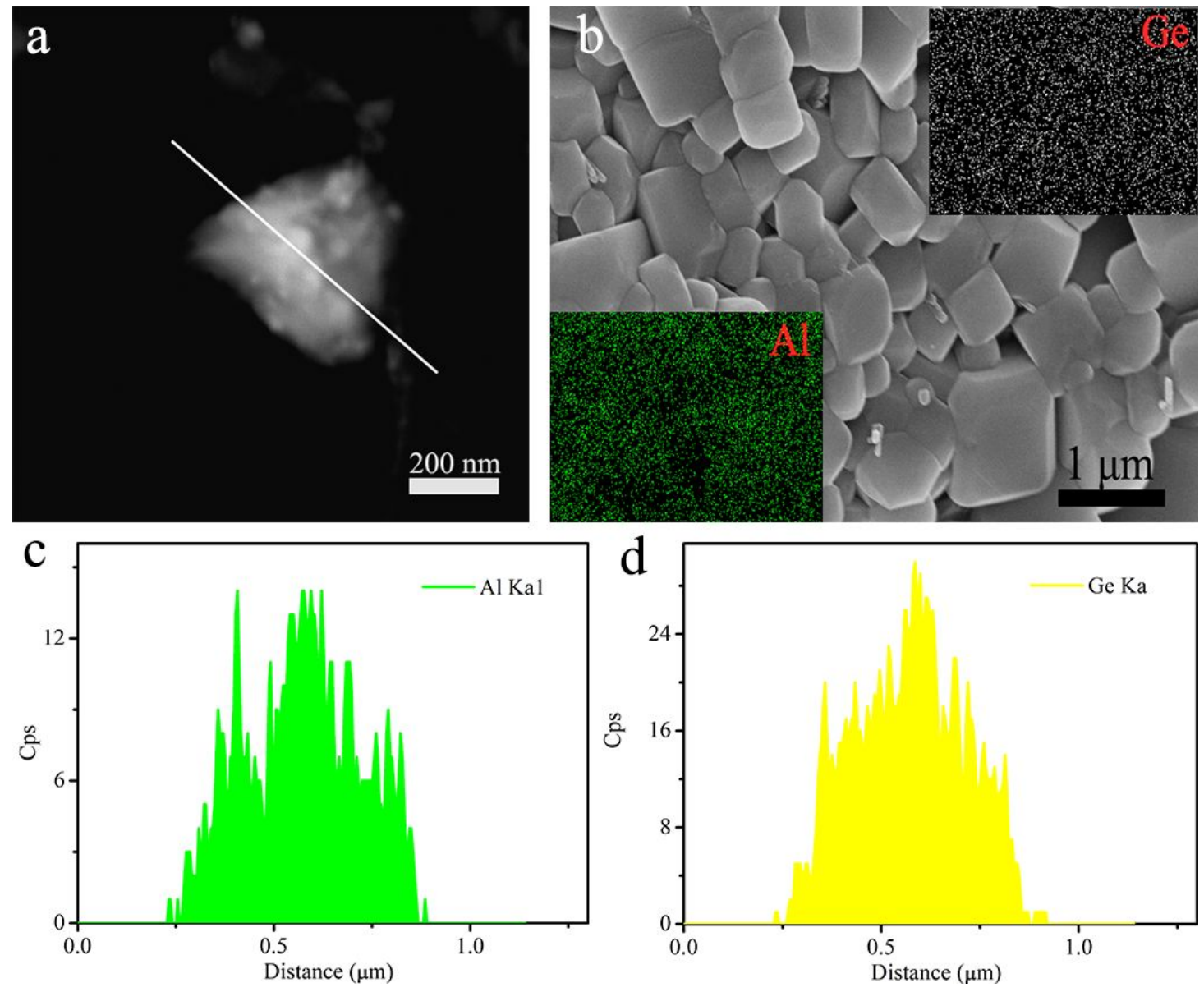

Figure S1 (a) TEM image of LAGP particle. (b) SEM image of LAGP particles before

ball milling and corresponding elemental mapping of Ge and Al. (c-d) Line sweep of 
Ge and Al elements of (a).

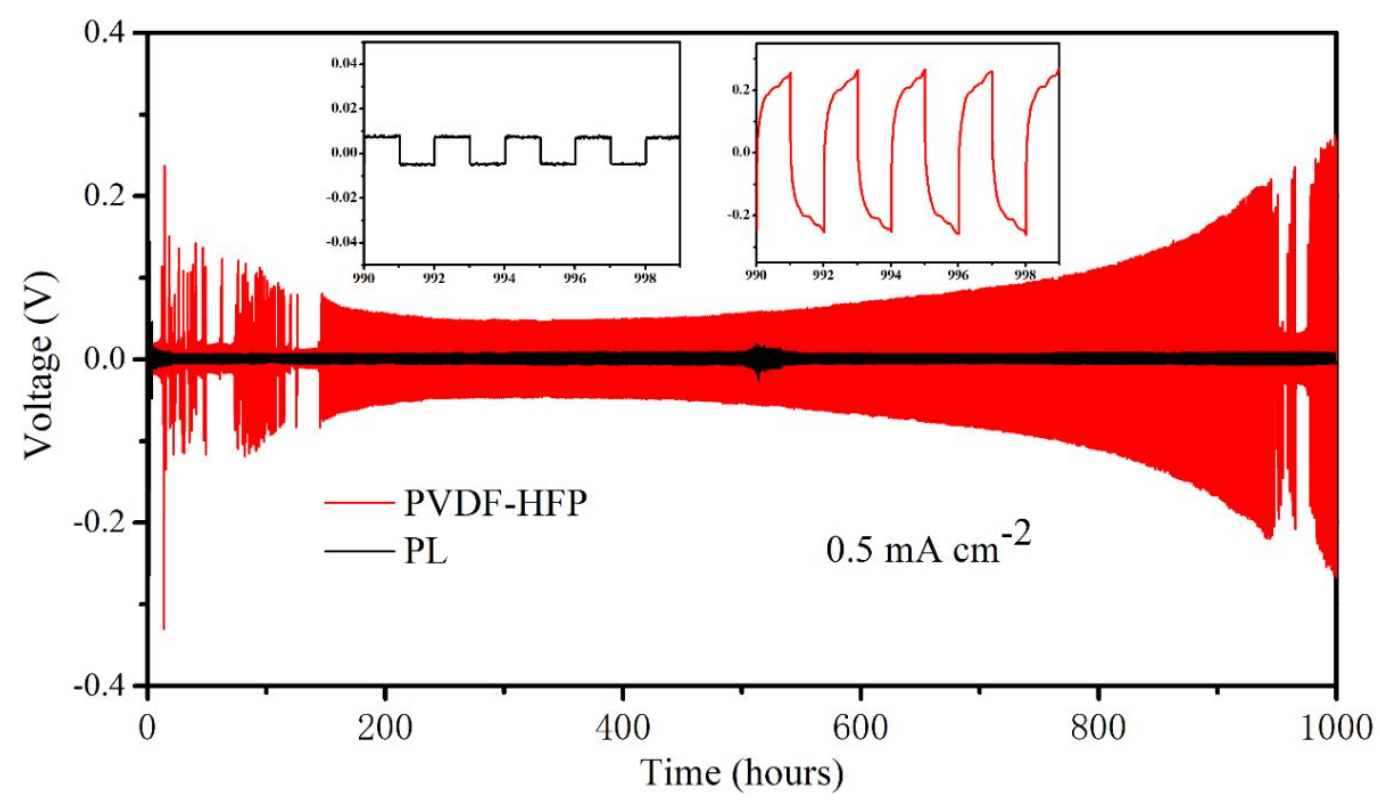

Figure S2 galvanostatic cycling profiles of symmetric Li/PVDF-HFP/Li and $\mathrm{Li} / \mathrm{PL} / \mathrm{Li}$

at current densities of $0.5 \mathrm{~mA} \mathrm{~cm} \mathrm{~cm}^{-2}$.

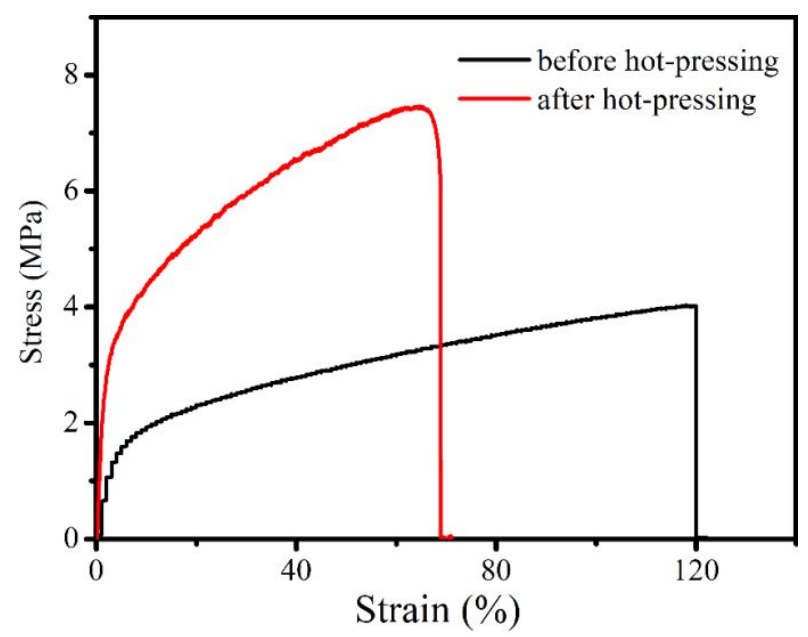

Figure S3 Stress-strain behavior of PL separators before and after hot pressing.

Table S1. Basic Properties of PL and $h p$-PL Separators

\begin{tabular}{cccccc}
\hline $\begin{array}{c}\text { Separator } \\
\text { code }\end{array}$ & $\begin{array}{c}\text { Thickness } \\
(\mu \mathrm{m})\end{array}$ & $\begin{array}{c}\text { Stress } \\
(\mathrm{MPa})\end{array}$ & $\begin{array}{c}\text { Uptake } \\
(\%)\end{array}$ & Porosity $(\%)$ & $\begin{array}{c}\text { Ionic conductivity } \\
\left(\mathrm{mS} \mathrm{cm}^{-1}\right)\end{array}$ \\
\hline$h p-\mathrm{PL}$ & 38 & 7.46 & 187 & 64 & 1.53 \\
$\mathrm{PL}$ & 85 & 4.03 & 215 & 70 & 3.18 \\
\hline
\end{tabular}

